\title{
Growth Performance and Food Conversion Efficiency of Juvenile Russian Sturgeon at Different Feeding Frequencies
}

\author{
Raluca-Cristina ANDREI (GURIENCU) ${ }^{1 *}$, Victor CRISTEA ${ }^{1}$, Lorena DEDIU ${ }^{1}$, Mirela CREȚU ${ }^{1}$ and Angelica \\ DOCAN $^{1}$

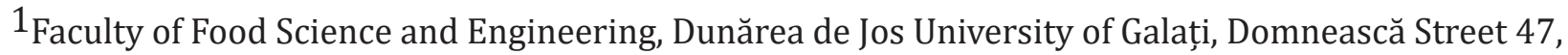 \\ Galați, Romania \\ *Corresponding author, e-mail: raluca.andrei@ugal.ro
}

Bulletin UASVM Animal Science and Biotechnologies 74(2)/ 2017

Print ISSN 1843-5262; Electronic ISSN 1843-536X

DOI:10.15835/buasvmcn-asb: 0009

\begin{abstract}
The effects of different feeding frequencies (one, two, three and four meals per day) on growth performance and feed conversion efficiency of Russian sturgeon juveniles (Acipenser gueldenstaedtii) was studied over a period of 45 days. The experiment took place in a recirculating aquaculture system provided with eight rearing units. 160 Russian sturgeon juveniles with an initial weight of $349.81 \pm 34.56 \mathrm{~g}$, were randomly distributed, in order to create four experimental variants in duplicate. At the end of the experiment all fish were weight and measured and the growth parameters were calculated. The results indicated that fish fed twice and once per day had the highest growth performance compared to fish feed with three and four meals/day. It was concluded that choosing a feeding frequency of two meals per day is much more sustainable in terms of economic costs.
\end{abstract}

Keywords: Russian sturgeon, feeding frequencies, growth performance

\section{INTRODUCTION}

The last decades of the 20th century witnessed a rapid decline in the size of natural populations of numerous sturgeons, which had been sources of valuable meat and caviar. The main reasons for the decline are, dam construction (for hydroelectric power), loss of spawning grounds, overfishing and water pollution (Steffens et al., 1990). The decline has, however, boosted interest in the controlled Acipenserid culture (Jankowska et al., 2002).

In worldwide sturgeon aquaculture, Russian sturgeon farming occupies a high proportion because of its superior meat and caviar quality among all sturgeons, with one exception, beluga's caviar, which has an exquisite taste and greater nutritive quality.

Currently, in the Romanian waters are found 3 species of migratory marine sturgeons, namely: Beluga (Huso huso Linnaeus, 1758), Russian sturgeon (Acipenser gueldenstaedtii Brand, 1833) and Stellate surgeon (Acipenser stellatus Brand, 1833), as well as sedentary fresh water species, the Sterlet (Acipenser ruthenus Linnaeus, 1758). Other sturgeons that we can find only in aquaculture environment are: the Bester, an artificial hybrid between the female of the Beluga and the male of Sterlet, the American planktonophagous paddlefish (Polyodon spathula, Walbaum, 1792), a fresh water sturgeon acclimated in Romania in 1992, and newly introduced Siberian sturgeon (Acipenser baerii, Brand, 1869) (Dediu et al., 2011).

In a fish farm feeding cost is the higer cost, representing almost $50 \%$ from all the cost. Feeding frequency is one of the most important factors affecting the growth rate and feed efficiency of fishes (Brett, 1979; Brett \& Groves, 1979). Good feeding management, including appropriate feeding frequency, can reduce overfeeding and 
Tab. 1. Proximate composition (\%) of the feed

\begin{tabular}{cc}
\hline Parameters & Quantity \\
\hline Crude protein (\%) & 42 \\
\hline Crude fat (\%) & 18 \\
\hline Crude cellulose (\%) & 1.2 \\
\hline Ash (\%) & 6.1 \\
\hline Phosphorus (\%) & 0.9 \\
\hline Vitamin A (IU) & 10 \\
\hline Vitamin C (mg Kg-1) & 150 \\
\hline Vitamin E (mg Kg-1) & 200 \\
\hline Vitamin D3 (IU) & 2430 \\
\hline Ingredients: fish meal, soybean extracts, maize gluten, rape oil, hemoglobin, wheat gluten, blood meal.
\end{tabular}

improve efficiency in fish culture (Riche et al., 2004).

The effects of feeding frequency on fish growth and feed conversion efficiency have been studied for several fish species. These studies show variable results among and within species because regimes are age and size dependent. For example, Rainbow trout ( $5.53 \mathrm{~g}$ ) fed two times had similar growth performance indicators as those fed four times (Dediu et al., 2011). Also, juvenile Great sturgeon (Huso huso) (900 g) that are fed three, four and five times per day showed a better growth and feed efficiency when fed less (Mohseni et al., 2006). Juvenile stellate sturgeon (Acipenser stellatus) (97 g) showed increased growth rates and a better welfare state as frequency of feeding was increased (Dicu et al., 2013). Channel catfish Ictalurus punctatus (53 g) grew more slowly when fed to satiation once per day then when fed two or four times per day; however, there were no differences in food conversion (Andrews and Page, 1975). No differences in overall growth or feed conversion were exhibited by small channel catfish (26 g) fed a 3\% ration in one or two feedings per day (Jarboe and Grant, 1997). However, larger channel catfish (219 g) fed twice per day had greater weight gain, specific growth rates (SGRs), and feed conversion than those fed once per day.

The aim of this study was to evaluate the effects of the different feeding frequencies to Russian sturgeon juveniles, reared in a recirculating aquaculture system, over a 45-days experimental period on the growth performance and food conversion. By investigating this sturgeon species, we were able to achieve an interesting perspective on species requirements for feeding frequencies.
Identification of feeding frequencies that give us information about a good growth performance should provide much needed data for culture and conservation programs.

\section{MATERIALS AND METHODS}

Experimental design. 160 Russian sturgeon juveniles were acclimated to the experimental rearing system for 2 weeks prior to the experiment. During this period, the fish were fed to satiation with the experimental diet every day (Table 1 ).

The experiment took place in a recirculating aquaculture system (RAS) during 45 days. 160 fish, with the mean initial weight of $349.81 \pm 0.84$ $\mathrm{g}$, were distributed equally in 8 rearing tanks (20 fish/rearing unit) in order to create four experimental variants, in duplicate. Fish were fed manually, with $2 \%$ B.W. The four experimental variants were: V1- 1 meal/day $\left(9^{\circ \circ}\right)$, V2- 2 meals/ day $\left(9^{\circ \circ} ; 15^{\circ \circ}\right)$, V3-three meals/day $\left(9^{\circ \circ} ; 12^{\circ \circ} ; 15^{\circ \circ}\right)$ and V4- four meals/day $\left(9^{\circ \circ} ; 12^{\circ \circ} ; 15^{\circ \circ} ; 18^{\circ \circ}\right)$. In the first experimental treatment, fish were fed and observed over an hour, ensuring equal distribution of the feed and to make sure that feed is not wasted.

After 25 days, fish were weighted and the ration size was adjusted according to the body weight. During the experiment fish were kept under a natural photoperiod of approximately $12 / 12$ h light/dark cycle and no mortality was registered.

Throughout the experimental period the most important water parameters were monitored daily with integrated sensors from the RAS system (temperature - $\mathrm{T}, \mathrm{pH}$, and dissolved oxygen-DO). The nitrogen compound $\left(\mathrm{N}-\mathrm{NO}_{2}{ }^{-}, \mathrm{N}-\mathrm{NO}_{3}{ }^{-}, \mathrm{N}-\mathrm{NH}_{4}^{+}\right.$, 


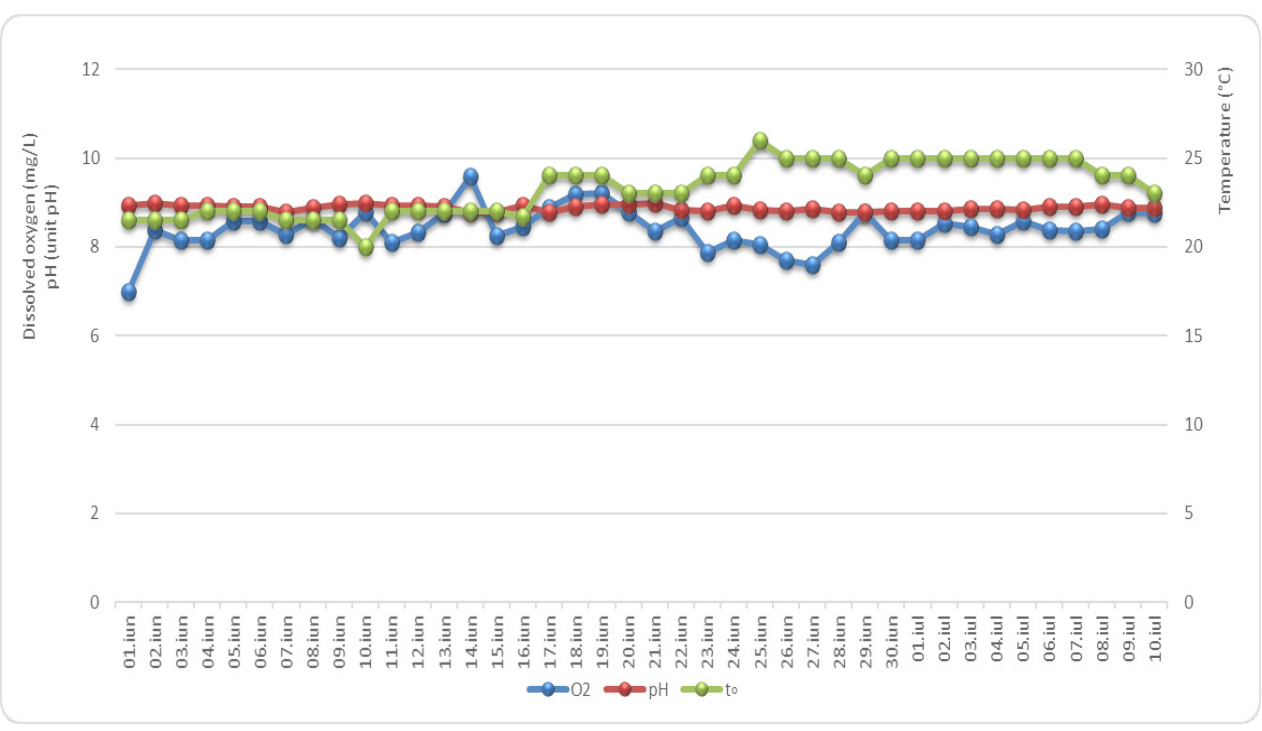

Fig. 1. Daily values of Oxygen, $\mathrm{pH}$ and temperature registered during the experiment.

were determined using Spectroquant Nova 400 spectrophotometer, compatible with Merk kits.

All fish were weighted individually at the beginning and end of the experiment to determine the following indicators: body weight $\mathrm{W}$, total length - TL, fork length - FL, standard length - SL. All measurements were made using anaesthetized fish ( $0.3 \mathrm{ml} \mathrm{L}^{-1}$ of 2-phenoxyethanol).

From the data obtained during the experiment, the following variables were calculated:

- Weight Gain (WG)=Final Weight (Wt1)Initial Weight (Wt0) (g),

- Feed Conversion Ratio (FCR)=Total feed (F)/Total weight gain (W),

- Specific Growth Rate (SGR (\%Body weight day $\left.\left.^{-1}\right)\right)=[(\operatorname{Ln} W \mathrm{t} 1-\mathrm{Ln} \mathrm{Wt} 0) / \mathrm{t}] \times 100$,

- Protein Efficiency Ratio (PER)= wet weight gain $(\mathrm{g}) /$ total protein intake.

- Thermal-unit Growth Coefficient (TGC) = (Wt1/3- Wt0/3) $/ \Sigma$ water temperature $\left({ }^{\circ} \mathrm{C} \mathrm{x}\right.$ days) $\mathrm{x} 100$.

Total length (TL) and body weight (W), for each variant, were used to determine the relationship $\mathrm{W}=\mathrm{a} \mathrm{L}^{\mathrm{b}}$, where "a" is the intercept (the initial growth coefficient) and " $b$ " is the allometric coefficient (Ricker, 1975).

Statistical data processing. Data were analyzed using SPSS version 17. One-way ANOVA and Duncan's multiple range tests were used to compare the differences between the experimental groups. Statistical differences between variables were tested using Anova $(\mathrm{p}<0.05)$.

\section{RESULTS AND DISSCUSIONS}

Water quality. During the experiment, all parameters were similar in all variants, without significant differences $(p>0.05)$. The daily values of temperature, oxygen and $\mathrm{pH}$ are represented graphically in Figure 1. Regarding the dynamics of water nitrogen compounds, the average values of nitrate, nitrite and ammonium concentrations were as follows: $21.60 \pm 0.15 \mathrm{mg} \mathrm{L}^{-1}, 0,04 \pm 0,0 \mathrm{mg}$ $\mathrm{L}^{-1}, 0,23 \pm 0,09 \mathrm{mg} \mathrm{L}^{-1}$.

During the study, the values were within tolerable limits for sturgeon growth and health (Mims et al., 2002).

Fish growth. Fish growth performance and feed efficiency are presented in Table 2. The increase in fish weight over the experimental period is shown in Figure 2. No significant differences were registered at the initial moment between each experimental variant $(p>0.05)$.

After 23 experimental days, all the fish were individual weight, and also no significant differences were observed ( $p>0.05)$. After 45 days, although the body weight recorded slightly higher values in the V2 variant, these were not statistically significant $(\mathrm{p} \geq 0.05)$.

The best food conversion ratio and protein efficiency ratio were observed in groups fed once and two times/day, however, no significant differences $(p>0.05)$ were noticed in all the other feeding regimes.

Also, individual weight gain in the group fed two times/day was slightly higher than weight 
Tab. 2. Fish growth performance and feed efficiency

\begin{tabular}{ccccc}
\hline Experimental variants & V1 & V2 & V3 & V4 \\
\cline { 2 - 5 } Growth performance & Mean \pm SD & Mean \pm SD & Mean \pm SD & Mean \pm SD \\
\hline Initial biomass (g) & $6999 \pm 6.36$ & $6978 \pm 29.7$ & $6999 \pm 1.41$ & $7010 \pm 4.95$ \\
\hline Initial number of fish & 20 & 20 & 20 & 20 \\
\hline Mean initial weight (g/ex) & $349.93 \pm 0.32$ & $348.90 \pm 1.48$ & $349.95 \pm 0.07$ & $350.48 \pm 0.25$ \\
\hline Final biomass (g) & $12328 \pm 262.34$ & $12797 \pm 103.24$ & $11964 \pm 229.1$ & $12095 \pm 152.03$ \\
\hline Final number of fish & 20 & 20 & 20 & 20 \\
\hline Mean final weight (g/ex) & $616.38 \pm 13.12$ & $639.85 \pm 5.16$ & $598.20 \pm 11.46$ & $604.73 \pm 7.60$ \\
\hline Individual weight gain (g/ex) & $266.5 \pm 12.8$ & $291.0 \pm 6.65$ & $248.3 \pm 11.38$ & $254.3 \pm 7.35$ \\
\hline Total weight gain (g) & $5329 \pm 255.97$ & $5819.0 \pm 132.94$ & $4965 \pm 227.69$ & $5085 \pm 147.08$ \\
\hline SGR- Specific growth rate (\%BW/day) & $1.42 \pm 0.05$ & $1.52 \pm 0.03$ & $1.34 \pm 0.05$ & $1.36 \pm 0.03$ \\
\hline FCR - Food conversion rate (g/g) & $0.99 \pm 0.05$ & $0.91 \pm 0.02$ & $1.06 \pm 0.05$ & $1.04 \pm 0.03$ \\
\hline PER- Protein efficiency ratio (g/g) & $2.41 \pm 0.12$ & $2.63 \pm 0.06$ & $2.24 \pm 0.1$ & $2.30 \pm 0.07$ \\
\hline Thermal-unit growth coefficient & $1.57 \pm 0.06$ & $1.69 \pm 0.04$ & $1.48 \pm 0.06$ & $1.51 \pm 0.04$ \\
\hline
\end{tabular}

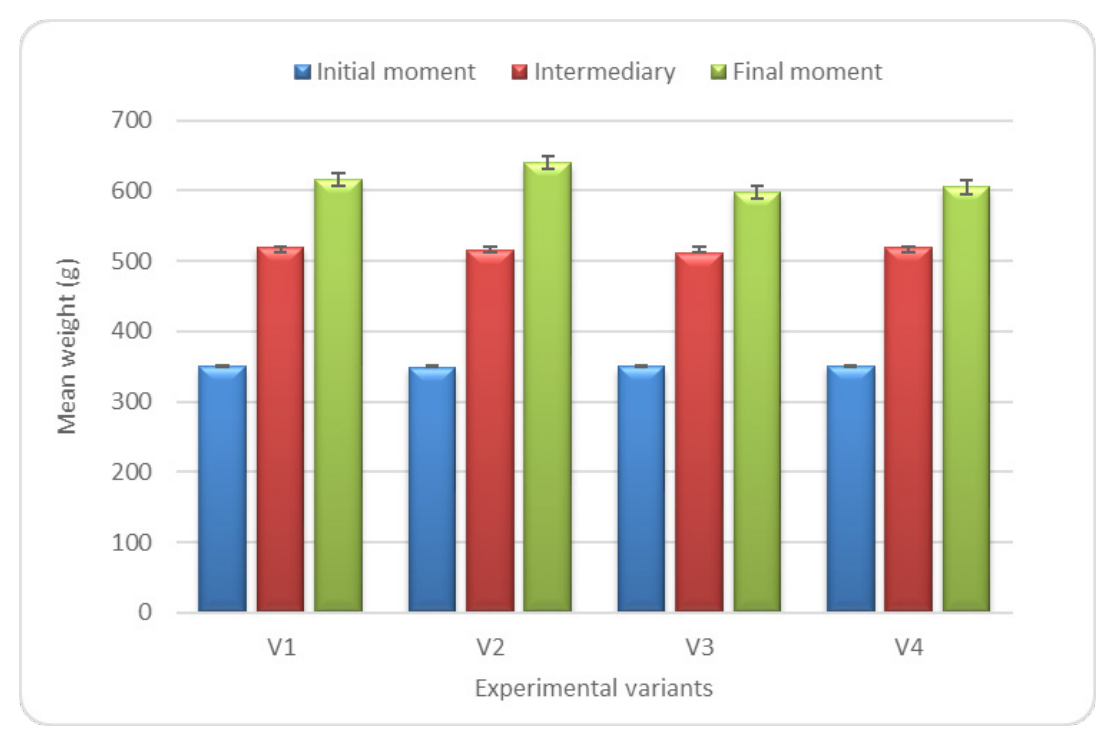

Fig. 2. Evolution of average means weight during the experimental period.

gain in other three groups, but differences were not statistically significant $(p>0.05)$. In our experiment the overall trend is that by decreasing the number of meals the growth performance improves. Results indicate that feeding frequencies from this experimental design had minimal or no effect on FCR in juvenile Russian sturgeon.

Thermal-unit growth coefficient (TGC) is considered a more stable index of growth, not affected by the size and water temperature and it changes with fish size and feed characteristics (Bendiksen et al., 2002). The TGC calculated for this experiment didn't vary much between variants and ranged between $1.48 \pm 0.06$ and $1.69 \pm 0.04$.
In order to evaluate fish condition, we made the power regression of the individual weight and length of all the fish from the experimental groups. A negative allometric grow $(b<3)$ can be seen in all experimental groups, the increase in length being faster than the increase in body weight. The condition of the fish from the V3 and V2 variant is better than those from the variant V2 and V4.

The effects of feeding frequency on fish growth and feed conversion efficiency have been studied for several species. It is important to determine the appropriate feeding schedule and ration to minimize cost of production while maximizing growth (Goddard, 1996). Results of these studies 


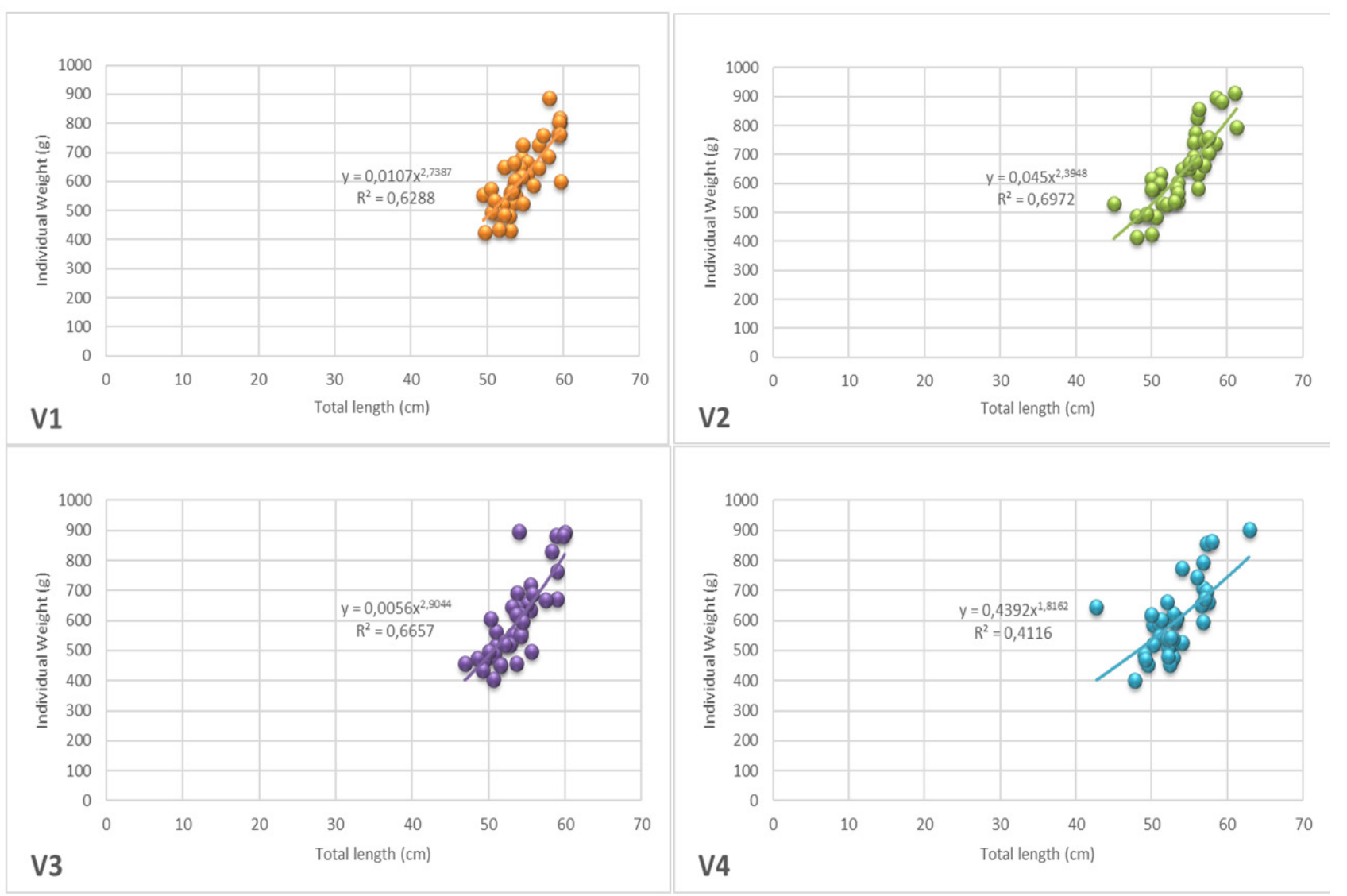

Fig. 3. Length-weight regression at the end of the experiment

are widely variable because different frequencies were applied among fish species; within a fish species over time, at different temperatures, water qualities, culture systems, fish size, feed rations (Ustaoğlu et. al, 2009; Stickney, 1994; Goddard, 1996).

In this study, a restricted daily ratio ( $2 \%$ body weight) was used to investigate the effect of feeding frequency (one, two, three and four times/day) on the growth of the Russian sturgeons. Increasing the feeding frequency from one to for times/day did not significantly affect the growth performance of Russian sturgeon. Overall, Russian sturgeon fed at all regimes showed a similar growth. The $2 \%$ ration provided sufficient food for the fish in this experiment; however, further research on the relationship between feeding frequency and different rations should be explored.

Because feeding frequency it's an important factor affecting the fish growth, it has been tested in many different fish species (Andrews and Page, 1975; Grayton and Beamish, 1977; Marian et al., 1981; Buurma and Diana, 1994; Lee et al., 2000).
Results of these studies are usually variable because different feeding frequency regimes were used among fish species, at different temperatures, different age, different water qualities, and in different culture systems. Andrews and Page (1975) found that growth of channel catfish (53 g B.W.) did not differ in fish hand-fed to satiation four times per day instead of two times per day, only one time per day negatively affected growth. When walking catfish, Clarias fuscus $(37,4$ g B.W.) were fed at a fixed ration of 3\% B.W. per day, three feedings per day produced significantly more growth than feeding once per day (Buurma and Diana, 1994). Channel catfish on a $2 \%$ ration grew faster as feeding frequency increased (Greenland and Gill, 1979). Juvenile fossil catfish, Heteropneustes fossilis, showed significantly greater growth when fed once or twice a day to satiation than when fed once in 2 or 3 days (Marian et al., 1981).

The results of this study suggest that feeding one or two times per day minimize effort while maximizing growth, in the same time, to decrease 
the ammonia problem on recirculating systems, it is indicated to split the daily portions (e.g., at least two times per day).

This study provides much needed information about the culture of Russian juveniles. Progress of feeding strategies for this sturgeon is the key to their prosperous culture. Rearing this protected species will be necessary to provide products that are in worldwide demand and, if necessary, fish for stocking programs.

Acknowledgements: This work was supported by a grant from the Romanian National Authority for Scientific Research and Innovation, CNCS/CCCDI - UEFISCDI, project number PN-IIIP2-2.1-BG-2016-0417, within PNCDI III".

\section{CONCLUSIONS}

Our results suggest that there may be a benefit in feeding juvenile Russian sturgeon with a feeding frequency of two portions over the day. Feeding one time can be difficult because there is no assurance over the feed consumed, especially because sturgeons are feeding slowly at the bottom of the tank. Such treatment seems suitable for rearing this species from $349.81 \pm 0.66 \mathrm{~g}$ to $614.79 \pm 18.3 \mathrm{~g}$.

\section{REFERENCES}

1. Andrews J W, Page J W, (1975). The effects of frequency of feeding on culture of catfish. Transactions of the American Fisheries Society, 2, pp. 317-321.

2. Bendiksen EA, Jobling M, Arnesen AM, (2002), Feed intake of Atlantic salmon parr Salmo salar L. in relation to temperature and feed composition. Aquac.Res., 33, pp. 525-532.

3. Brett JR (1979). Environmental factors and growth. In: Fish Physiology. Bioenergetics and Growth, vol. VIII (Hoar, W.S., Randall, D.J. \& Brett, J.R. eds), Academic Press, New York, pp. 599-675.

4. Buurma BJ, Diana JS (1994). Effects of feeding frequency and handling on growth and mortality of cultured walking catfish Clarias fuscus. Journal of the World Aquaculture Society, 25, pp.175-182.

5. Dediu L, Cristea V, Mocanu M, Dicu D, Docan A, Grecu I (2011). The effect of feeding frequency on growth performance of rainbow trout fingerlings reared in recirculating system. AACL Bioflux, 4, pp.141-145.

6. Dicu MD, Cristea V, Docan A, Grecu I, Dediu L, Coadă MT (2013). The influence of feeding frequency on the haematological profile of A. stellatus (Pallas 1771), reared in a recirculating aquaculture system. Revista "Lucrări ştiinţifice. Seria Zootehnie", 59, pp.242-246.
7. Goddard S (1996) Feed management in intensive aquaculture. Chapman and Hall, New York.

8. Grayton BD, Beamish FWH (1977). Effects of feeding frequency on food intake, growth and body composition of rainbow trout (Salmo gairdneri). Aquaculture, 11, pp.159-172.

9. Greenland DC, Gill RL (1979). Multiple daily feedings with automatic feeders improve growth and feed conversion rates of channel catfish. Progressive FishCulturist, 41, pp.151-153.

10. Jankowska B, Kwiatkowska A, Kolman R, Szczepkowska B (2002). A comparison of certain characteristics of meat of the Siberian sturgeon (A.baerii Brandt) and that of its hybrids with the green sturgeon $(A$. medirostris Ayers). Electronic Journal of Polish Agricultural Universities, 5, Issue 1, AvailableOnline http://www. ejpau.media.pl.

11. Jarboe HH, Grant WJ (1997). The influence of feeding time and frequency on the growth, survival, feed conversion, and body composition of channel catfish, Ictalurus punctatus, cultured in a three-tier, closed, recirculating raceway system. Journal of Applied Aquaculture, 7, pp.43-52.

12. Lee SM, Cho SH, Kim DJ, (2000). Effects of feeding frequency and dietary energy level on growth and body composition of juvenile flounder, Paralichthys olivaceus (Temminck \& Schlegel). Aquaculture Research, 31, pp.917-921.

13. Marian MP, Ponniah AG, Pitchairaj R, Narayanan M (1981). Effect of feeding frequency on surfacing activity and growth in the air-breathing fish, Heteropneustes fossilis. Aquaculture, 26, pp.237-244.

14. Mims SD, Lazur A, Shelton WL,Gomelsky B, Chapman F (2002). Species profile production of sturgeon. Southern Regional Aquaculture Center SRAC, publ. no. 7200, http://fisheries.tamu.edu/files/2013/09/SRACPublication-No.-7200-Species-Profile-Production-ofSturgeon1.pdf.

15. Mohseni M, Pourkazemi M, Bahmani M, Falahatkar B, Pourali HR, Salehpour M (2006). Effects of feeding rate and frequency on growth performance of yearling great sturgeon, Huso huso. J. Appl. Ichthyol., 22, pp. 278-282.

16. Piper RG (1982). Fish hatchery management. U.S. Development of the Interior, Fish and Wildlife Service, Washington, DC, USA.

17. Riche M, Oetker M, Haley DI, Smith T, Garling DL (2004). Effect of feeding frequency on consumption, growth, and efficiency in juvenile tilapia (Orechromis niloticus). Israeli J. Aquacult.-Bamidgeh, 56, pp. 247-255.

18. Ricker WE (1975). Computation and interpretation of biological statistics of the fish population. Bulletin of the Fisheries Research Board of Canada, 191, pp.1-382.

19. Steffens W, Jahnichen H, Fredrich F (1990). Possibilities of sturgeon culture in Central Europe. Aquaculture, 89, pp. 101-122. 
20. Stickney RR (1994). Principles of aquaculture. Wiley, New York.

21. Tsevis, N, Klaoudatos S, Conides A (1992). Foodconversion budget in sea bass, Dicentrarchus labrax, fingerlings under two different feeding frequency patterns. Aquaculture, 101, pp. 293-304.
22. Ustaoğlu TS, Alagil F (2009). Effects of feeding frequency on nutrient digestibility and growth performance of rainbow trout (Oncorhynchus mykiss) fed a high lipid diet. Turk. J. Vet. Anim. Sci., 33(4), pp. 317-322. 